\title{
Tetramethylpyrazine suppresses lipid accumulation in macrophages via upregulation of the ATP-binding cassette transporters and downregulation of scavenger receptors
}

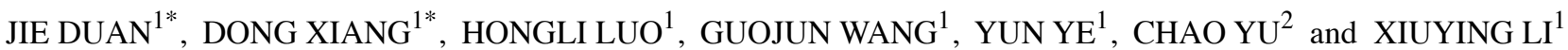 \\ ${ }^{1}$ Department of Pharmacy, Affiliated Hospital of Southwest Medical University, Luzhou, Sichuan 646000; \\ ${ }^{2}$ College of Pharmacy, Chongqing Medical University, Chongqing 400016, P.R. China
}

Received February 17, 2017; Accepted July 25, 2017

DOI: $10.3892 / o r .2017 .5881$

\begin{abstract}
Tetramethylpyrazine (TMP), a biologically active ingredient first extracted from the Chinese medicinal plant Ligusticum wallichii Franchat., has athero-protective activity, yet the particular mechanisms have not been completely explored. The present study was designed to investigate the effect of TMP and its possible mechanisms in RAW264.7 macrophages and apolipoprotein E-deficient $\left(\mathrm{ApoE}^{-/}\right)$mice. TMP treatment markedly increased the cholesterol efflux and inhibited oxidized low-density lipoprotein (ox-LDL) uptake, thus, ameliorating lipid accumulation in macrophages. In addition, TMP significantly increased the protein and mRNA expression of ATP-binding cassette transporters A1 (ABCA1) and $\mathrm{G} 1$ (ABCG1), while suppressing the protein and mRNA expression of class A scavenger receptor (SR-A) and the cluster of differentiation 36 (CD36). Moreover, the effects of TMP on the upregulation of the expression of ABCA1 and ABCG1, the downregulation of the expression of CD36 and SR-A, the increase of cholesterol efflux and the decrease of lipid accumulation as well as the uptake of ox-LDL were mediated by the inactivation of PI3K/Akt and p38 MAPK. Furthermore, TMP upregulated the protein stability of ABCA1 without affecting ABCG1. Accordingly, TMP regulated the expression of SR-A, CD36, ABCA1 and ABCG1 in aortas of $\mathrm{ApoE}^{-/-}$mice, which resembled the findings observed in macrophages. TMP was also capable of delaying the progression of atherosclerosis in ApoE $^{-/}$mice. These findings revealed that TMP downregulates scavenger receptors and upregulates ATP-binding cassette transporters via PI3K/Akt and p38 MAPK signaling, thus suppressing lipid accumulation in macrophages.
\end{abstract}

Correspondence to: Xiuying Li, Department of Pharmacy, Affiliated Hospital of Southwest Medical University, Luzhou, Sichuan 646000, P.R. China

E-mail: 1xy421421@163.com

*Contributed equally

Key words: tetramethylpyrazine, atherosclerosis, scavenger receptors, ATP-binding cassette transporters, macrophage

\section{Introduction}

Atherosclerosis, a major underlying factor in stroke and cardiovascular disease, crucial causes of mortality and morbidity worldwide (1), is a chronic arterial disease featuring lipid deposition and inflammation in the vessel wall (2). Formation of foam cells is the early event in atherosclerotic pathogenesis. In this stage, exorbitantly oxidized low-density lipoprotein (ox-LDL) uptake or damaged cholesterol efflux in macrophages is the leading cause of foam cell formation (3). Scavenger receptors (SRs) on macrophage membranes are responsible for ox-LDL uptake, such as cluster of differentiation 36 (CD36) and class A scavenger receptor (SR-A) (4). In addition, to lipid influx, efflux of intracellular lipids occurs mostly via reverse cholesterol transport (RCT). Several membrane proteins, such as SR-B type I (SR-BI) and ATP-binding cassette transporter A1 (ABCA1) and ABCG1, have been reported to play a critical role in the RCT pathway (5).

The cellular cholesterol efflux from tissues is dependent on extracellular lipid receptors including lipid-poor apoproteins and high-density lipoprotein (HDL) (6). ABCA1 promotes free cholesterol efflux from macrophages into apolipoprotein A1 (ApoA1), whereas ABCG1 plays a key role in mediating cholesterol efflux to HDL (7-9). Therefore, formation of foam cells is mainly regulated by the RCT pathway and SRs. Evidence has suggested that modulation of SRs or the RCT pathway by antioxidants prevents lipid accumulation in foam cells and then retards the progression of atherosclerosis $(10,11)$.

TMP, the predominant active ingredient in Rhizoma Ligustici wallichii (Chuanxiong), possesses antiproliferative and apoptosis-inducing activities in diverse cancer cell types (12-14). However, it has been reported that TMP was effective in the treatment of a few cardiovascular complications, including angina pectoris and cerebrovascular and thrombotic vascular diseases (15-17), as a result of its biological activities including vasodilation (17) and antiplatelet aggregation (18). Additionally, TMP exerts anti-atherosclerotic effects via inhibition of endothelial dysfunction (19), regulation of lipid levels in the plasma (20), attenuation of oxidative stress (21) and inflammation (22). However, the effects and molecular mechanisms involved in TMP-mediated lipid accumulation in macrophage-derived foam cells have not been well 
documented. In addition, a variety of genetic population research has highlighted the value of the p38 and PI3K/Akt signaling pathways in the promotion of human atherosclerotic lesions $(23,24)$.

However, whether p38 and PI3K/Akt are connected with the anti-atherogenic effect of TMP on foam cell formation warranted further investigation. In a recent study, we investigated the impact of TMP on atherosclerosis and the potential mechanisms in RAW264.7 cells (mouse macrophage cell line) and apolipoprotein E-deficient $\left(\mathrm{ApoE}^{-/}\right)$mice. We observed that TMP markedly inhibited not only the formation of foam cells in vitro, but also the atherosclerotic plaque area in aortas from $\mathrm{ApoE}^{-/-}$mice. The anti-atherosclerotic impact of TMP may be attributed to the upregulation of ABCA1 and ABCG1 and the downregulation of CD36 and SR-A by p38 MAPK and PI3K signaling.

\section{Materials and methods}

Reagents. TMP (purity, 98.0\%), cycloheximide (CHX), LY294002, SB203580 were purchased from Sigma-Aldrich (St. Louis, MO, USA). Goat anti-SR-A antibody (sc-166184, 1:2,000) and protein A/G-Sepharose were obtained from Santa Cruz Biotechnology, Inc. (Santa Cruz, CA, USA). Mouse anti-ABCA1 (ab7360; 1:800) as well as anti-p-AKT (ab38449; 1:800), anti-p-p38 (ab47363; 1:800), anti-ABCG1 (ab52617; 1:5,000), anti-CD36 (ab133625; 1:5,000), anti$\beta$-actin $(\mathrm{ab} 20272 ; 1: 5,000)$ and anti-SR-BI $(\mathrm{ab} 52629 ; 1: 2,000)$ rabbit antibodies were obtained from Abcam (Cambridge, MA, USA). Goat anti-mouse IgG (bs-0295GS; 1:2,000) and goat anti-rabbit IgG (bs-0296G; 1:2,000) were obtained from Bioss Biotechnology (Beijing, China). DiI-labeled ox-LDL and ox-LDL were purchased from Guangzhou Yiyuan Biotechnology Co., Ltd. (Guangzhou, China).

Cell culture. RAW264.7 was obtained from the American Type Culture Collection (ATCC; Manassas, VA, USA), and maintained in RPMI-1640 medium (Invitrogen, Carlsbad, CA, USA) with $10 \%$ fetal bovine serum in a $37^{\circ} \mathrm{C}$ incubator with $5 \% \mathrm{CO}_{2}$. TMP was dissolved in dimethyl sulfoxide (DMSO), and further diluted with complete RPMI-1640 medium (DMSO <0.1\%) for the treatment of in vitro cells. The control group was cultured in medium containing the same volume of DMSO.

Animals. Twenty mice (10 for each group) used in the present study were 8-week-old male $\mathrm{ApoE}^{-/}$mice $(22-24 \mathrm{~g} /$ mouse), from Jackson Laboratory (Bar Harbor, ME, USA), which were procured from Tengxin Technology Company (Chongqing, China), and were housed in barrier facilities on a $12-\mathrm{h}$ light/dark cycle. All experimental mice were permitted food and water ad libitum. The animal procedures were approved by the Animal Care and Use Committee of the Chongqing Medical University (Chongqing, China).

Animal experimental protocols. $\mathrm{ApoE}^{-/}$mice were orally treated for 8 weeks with TMP $(150 \mathrm{mg} / \mathrm{kg} / \mathrm{day})$ or vehicle ( $20 \mathrm{ml} / \mathrm{kg} /$ day, $0.5 \%$ sodium carboxyl methyl cellulose) by gastric gavages ( $\mathrm{n}=10$, each group), until being fed a high-fat diet $(15.8 \%$ fat and $1.25 \%$ cholesterol) for an additional 8 weeks. In the present study, we adopted TMP doses in accordance with a previous study (25). Mice were euthanized using $\mathrm{CO}_{2}$ following treatment with TMP (total diet-fed period was 16 weeks), and then the hearts and aortas were collected for Oil Red O staining and western blotting.

Cell viability assay with MTT. Macrophages were seeded in 96-well plates at a density of $7.5 \times 10^{4}$ cells/well and the cell viability via methyl thiazolyl tetrazolium (MTT) assay was detected. Before removing the culture supernatant, the cells were treated with or without TMP for $24 \mathrm{~h}$. The following steps were performed as previously described (26).

Assessment of foam cell formation by Oil Red O staining. Oil Red O staining was performed as previously described (3). After being washed $3 \mathrm{X}$ with phosphate-buffered saline (PBS), the cells were fixed in $4 \%$ paraformaldehyde for $20 \mathrm{~min}$, and then stained with $0.5 \%$ Oil Red O staining for $10 \mathrm{~min}$ to visualize cellular lipid accumulation. Light microscopy with a magnification of $\times 200$ was used to photograph the stained cells. After Oil Red O staining, alcohol extraction was used to detect the density of the lipid content. The absorbance at $500 \mathrm{~nm}$ was assessed using a microplate reader.

Cholesterol efflux assay. Cholesterol efflux was assessed as previously described (27). After pre-incubation with or without TMP for $24 \mathrm{~h}$, the RAW264.7 cells were labeled with $6 \mu \mathrm{g} / \mathrm{ml}$ BODIPY-cholesterol in medium containing $0.5 \% \mathrm{CD}$ (methyl- $\beta$-cyclodextrin) for $1 \mathrm{~h}$ at $37^{\circ} \mathrm{C}$. Next, the cells were washed with PBS, then incubated with serum/phenol red-free medium containing $10 \mu \mathrm{g} / \mathrm{ml} \mathrm{ApoA}-1$ and $10 \mu \mathrm{g} / \mathrm{ml} \mathrm{HDL}$ for $2 \mathrm{~h}$ at $37^{\circ} \mathrm{C}$ during the total cholesterol efflux experiments. In the ABCA1- or ABCG1-mediated cholesterol efflux experiments, the cells were incubated with serum/phenol red-free media containing $10 \mu \mathrm{g} / \mathrm{ml}$ ApoA-1 (for ABCA1) or $10 \mu \mathrm{g} / \mathrm{ml}$ HDL (for ABCG1) for $2 \mathrm{~h}$ at $37^{\circ} \mathrm{C}$. The collected medium was centrifuged at $2,000 \mathrm{x} \mathrm{g}$ for $10 \mathrm{~min}$ to remove the unattached cells. BODIPY-cholesterol fluorescence was detected with an excitation/emission wavelength of $485 / 515 \mathrm{~nm}$ using a Wallac 1420 VICTOR 2TM fluorometer (Perkin-Elmer, Inc., Waltham, MA, USA). The percentage of fluorescence in the medium relative to the total fluorescence (cells + medium) was used to calculate the cholesterol efflux.

DiI-Ox-LDL uptake. The DiI-Ox-LDL uptake assay was performed as previously described (27). RAW264.7 cells were treated with or without TMP for $24 \mathrm{~h}$, and then incubated in RPMI-1640 medium containing $10 \mu \mathrm{g} / \mathrm{ml}$ DiI-Ox-LDL for $4 \mathrm{~h}$ at $37^{\circ} \mathrm{C}$. The medium containing DiI-Ox-LDL was collected, and the cells were washed with probe-free medium. The fluorescence intensities of the medium and the cell lysates were detected with an excitation/emission wavelength of $514 / 550 \mathrm{~nm}$ using the Wallac 1420 VICTOR 2TM fluorometer.

Western blotting. Cells or tissues were collected and protein extracts were prepared as previously described (3). The proteins were applied to western blotting using primary antibodies. Then, a chemiluminescence method (Pierce Biotechnology, Inc., Rockford, IL, USA) and Quantity One (Bio-Rad, Hercules, CA, USA) software program were used to visualize and quantify the proteins. 


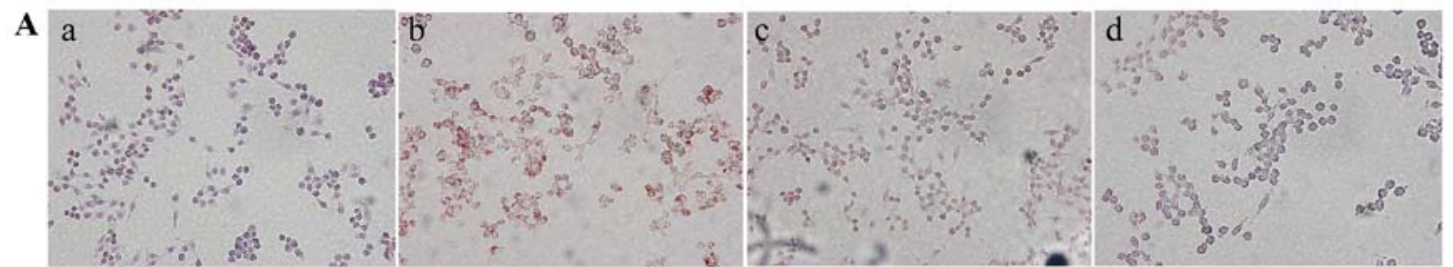

B

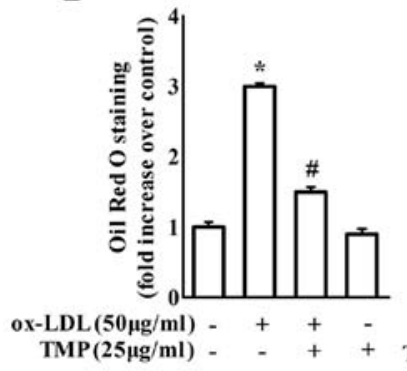

C

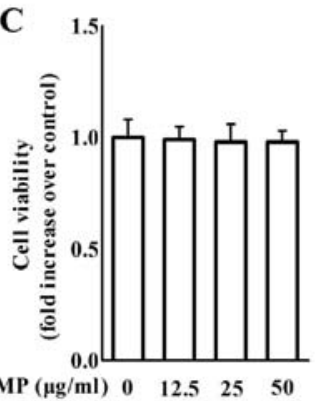

D

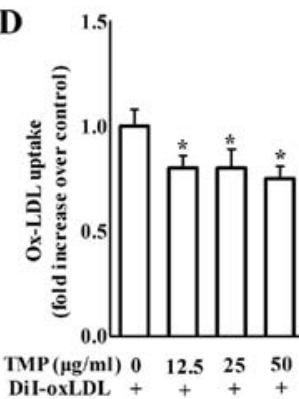

E

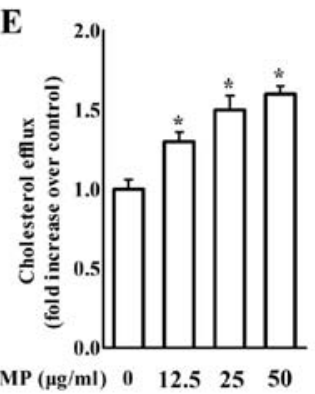

Figure 1. TMP at non-cytotxic concentrations without cytotoxicity inhibits lipid accumulation and promotes cholesterol efflux in RAW264.7 macrophages. (A) Macrophages were treated with ox-LDL $(50 \mu \mathrm{g} / \mathrm{ml})$ in the presence or absence of TMP ( $25 \mu \mathrm{g} / \mathrm{ml})$ for $24 \mathrm{~h}$. a, control group; b, the ox-LDL-treated group; c, the ox-LDL plus TMP group; d, the TMP-treated group. The cells with various treatments were fixed, and then stained with Oil Red O (magnification, $\mathrm{x} 400$ ). (B) After Oil Red O staining, alcohol extraction was used to detect the density of the lipid content. The absorbance at 500 nm was assessed with a microplate reader. (C) Macrophages were treated with TMP $(0,12.5,25$ and $50 \mu \mathrm{g} / \mathrm{ml})$ for $24 \mathrm{~h}$ and cell viability was assessed by MTT assay. (D) Macrophages were treated with TMP $(0,12.5,25$ and $50 \mu \mathrm{g} / \mathrm{ml})$ for $24 \mathrm{~h}$, and then incubated with $10 \mu \mathrm{g} / \mathrm{ml} \mathrm{DiI-Ox-LDL}$ for $4 \mathrm{~h}$ at $37^{\circ} \mathrm{C}$. The cell lysate and medium were collected to assess the absorbance at $540 \mathrm{~nm}$. (E) A cholesterol efflux assay was performed as described in the Materials and methods. The data are representative of 3 independent experiments (mean $\pm \mathrm{SEM}$ ); ${ }^{*} \mathrm{P}<0.05$ compared with control group; ${ }^{*} \mathrm{P}<0.05$ compared with ox-LDL-treated group. TMP, tetramethylpyrazine; ox-LDL, oxidized low-density lipoprotein; MTT, methyl thiazolyl tetrazolium.

Quantitative real-time polymerase chain reaction $(R T-q P C R)$. RT-qPCR was performed as previously described (26). Total RNA was isolated using TRIzol reagent (Invitrogen). cDNA synthesis was performed using MuLV reverse transcriptase (Applied Biosystems, Foster City, CA, USA). Real-time PCR was performed using a SYBR-Green PCR Master Mix kit (Tiangen Biotech Co., Ltd., Beijing, China). Primer sequences were as follows: ABCA1 forward, 5'-ggtttggagatggttatacaatagttgt-3' and reverse, 5'-cccggaaacgcaagtcc-3'; ABCG1 forward, 5'-ttcccetggagatgagtgtc-3' and reverse, 5'-cagtaggccacagggaacat-3'; SR-A forward, 5'-tggtccacctggtgctcc-3' and reverse, 5'-acctccagggaagcaattt-3'; CD36 forward, 5'-cagttggagacctgcttatcc-3' and reverse, 5'-gcgtcctgggttacattttc-3'; SR-BI forward, 5'-accctaacccaaaggagcat-3' and reverse, 5'-cacagcaacggcagaactac-3'; $\beta$-actin forward, 5'-ttgtccetgtatgcetctgg-3' and reverse, 5'-gaggtctttacggatgtcaacg-3'. The RT-qPCR reaction was performed under the following conditions: $3 \mathrm{~min}$ at $95^{\circ} \mathrm{C}$ for 1 cycle, $10 \mathrm{sec}$ at $95^{\circ} \mathrm{C}, 30 \mathrm{sec}$ at $60^{\circ} \mathrm{C}$ for 39 cycles, and $95^{\circ} \mathrm{C}$ for $5 \mathrm{sec}$.

Statistical analysis. Data are presented as the mean \pm SEM. Statistical analysis was carried out using one-way ANOVA followed by Bonferroni post hoc test or unpaired Student's t-test. Continuous variables were tested for normal distribution using the Kolmogorov-Smirnov test. Differences were considered statistically significant when $\mathrm{P}<0.05$. All calculations were carried out using SPSS 15.0 version (SPSS, Inc., Chicago, IL, USA).

\section{Results}

TMP enhances cholesterol efflux and suppresses lipid accumulation of RAW264.7 macrophages. An MTT assay was used to detect the toxicity of TMP on macrophages. The cell viability was unchanged with the treatment of TMP (12.5, 25 and $50 \mu \mathrm{g} / \mathrm{ml}$ ) for $24 \mathrm{~h}$ (Fig. 1C). Accordingly, we chose a concentration range of $12.5-50 \mu \mathrm{g} / \mathrm{ml}$ for subsequent research. Lipid accumulation was examined in macrophages with ox-LDL in the presence or absence of TMP, which is a sign of foam cell formation. The image results for foam cell formation are shown in Fig. 1A and B. TMP significantly inhibited lipid accumulation in macrophages.

Accordingly, TMP treatment caused a significant decrease in ox-LDL uptake and an increase in cholesterol efflux compared with the control group (Fig. 1D and E). These findings revealed that TMP inhibited foam cell formation by increasing cholesterol efflux and decreasing ox-LDL uptake in macrophages.

TMP decreases the expression of scavenger receptors and increases the expression of ABC transporters in RAW264.7 macrophages. We next examined the effects of TMP on the expression of scavenger receptors and $\mathrm{ABC}$ transporters, such as SR-A, CD36, SR-BI, ABCG1 and ABCA1, which play integral roles in intracellular lipid accumulation in RAW264.7 as a previous study demonstrated (27). Our findings revealed that treatment with $12.5-50 \mu \mathrm{g} / \mathrm{ml}$ TMP dose-dependently increased the mRNA and protein expression of ABCA1 and ABCG1 (Fig. 2). Additionally, the protein and mRNA levels of CD36 and SR-A in macrophages were significantly inhibited by TMP (Fig. 2). However, both the mRNA and protein levels of SR-BI were unchanged with treatment of TMP in macrophages (Fig. 2). Based on the results in Fig. 2, TMP may inhibit the formation of foam cells by regulating $\mathrm{ABC}$ transporters and scavenger receptors in RAW264.7 macrophages. 

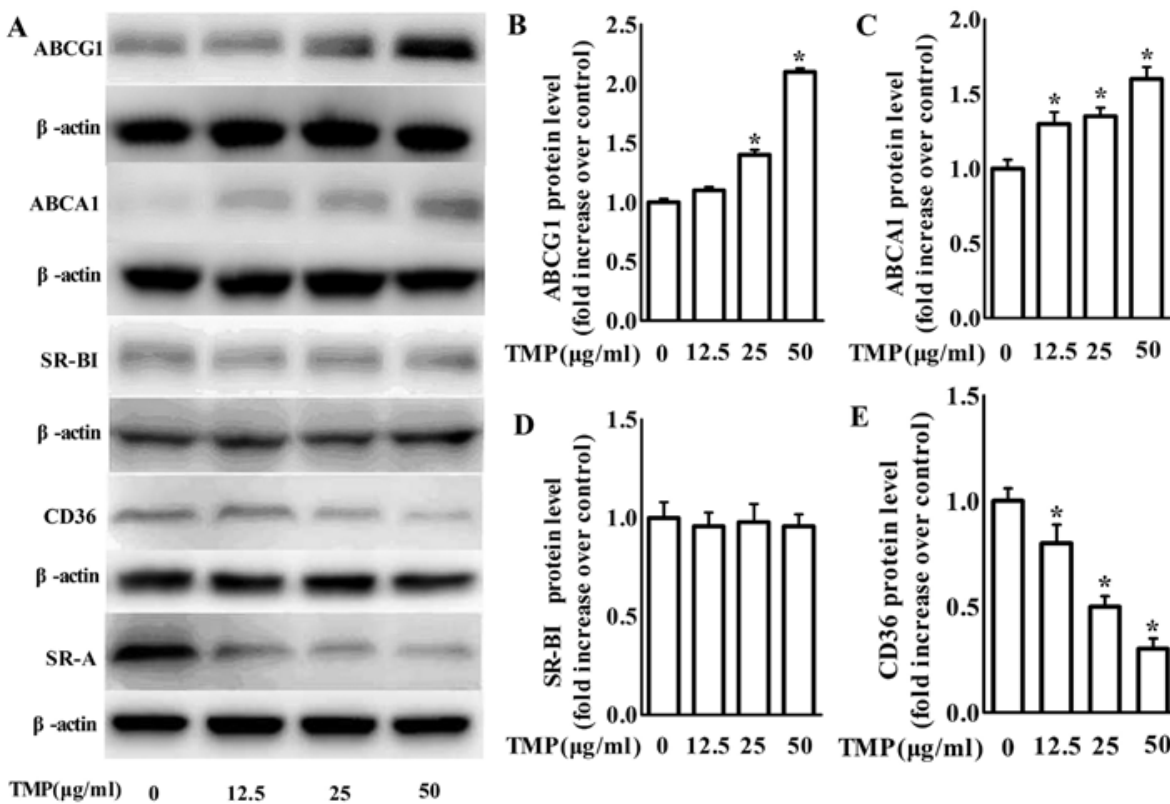

$\operatorname{TMP}(\mu \mathrm{g} / \mathrm{ml}) \quad 0 \quad 12.5 \quad 25 \quad 50$
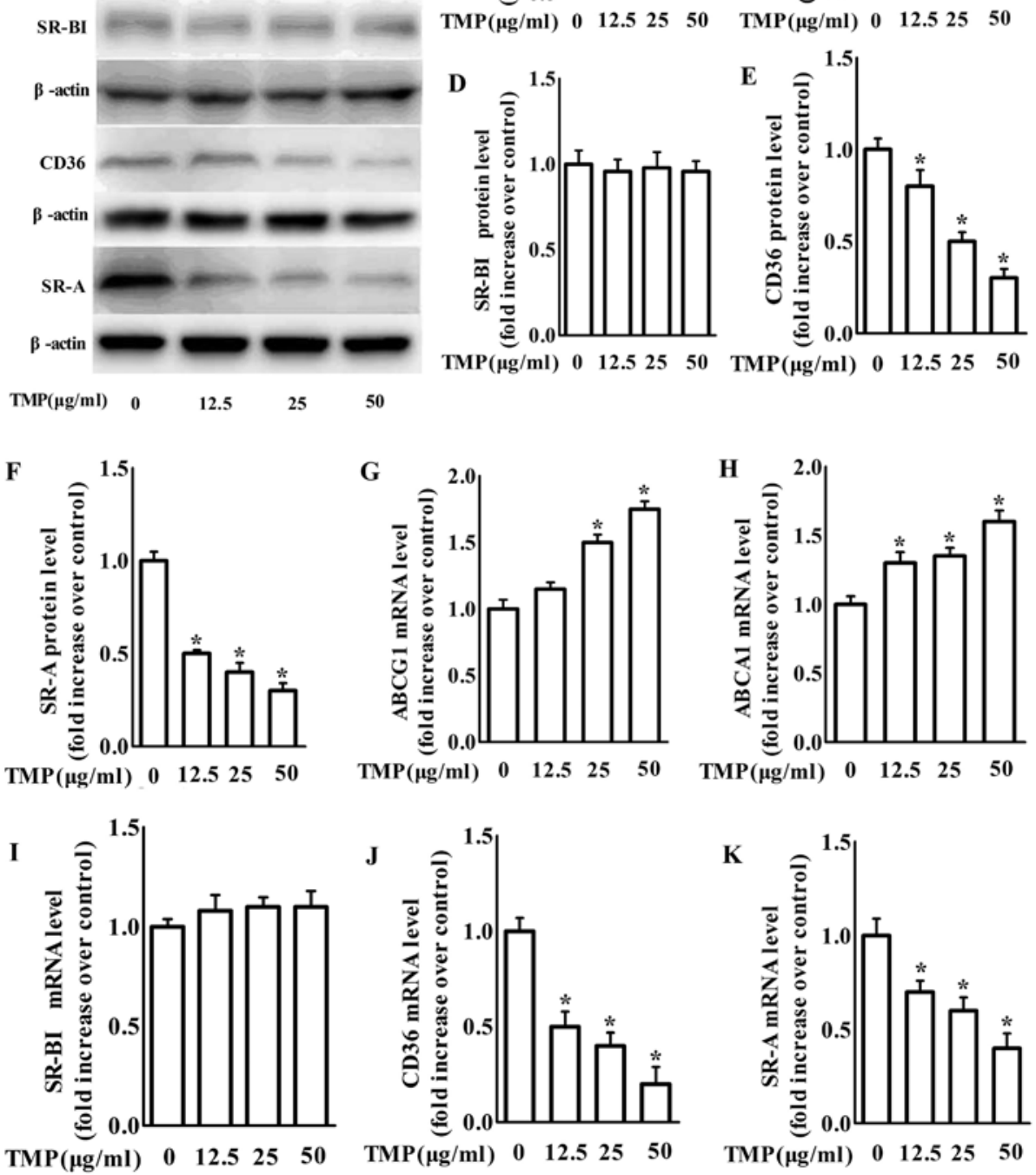

Figure 2. TMP decreases protein and mRNA expression of CD36 and SR-A, but increases protein and mRNA expression of the ABCA1 and ABCG1 in RAW264.7 macrophages. (A) Macrophages were treated with TMP $(0,12.5,25$ and $50 \mu \mathrm{g} / \mathrm{ml})$ for $24 \mathrm{~h}$ and the protein level of SR-A, CD36, SR-BI, ABCA1, ABCG1 or $\beta$-actin was determined by western blotting. (B-F) The relative protein levels of CD36, SR-A, SR-BI, ABCA1 and ABCG1 are presented as the mean \pm SEM of the optical density from 3 separate experiments. (G-K) After treatment, total RNA was extracted and then subjected to RT-qPCR to detect the mRNA expression of SR-A, CD36, ABCA1, ABCG1 and SR-BI. The data are representative of 3 independent experiments (mean \pm SEM); ${ }^{*}<0.05$ compared with the control group. TMP, tetramethylpyrazine; CD36, cluster of differentiation 36; SR-A scavenger receptor class A; ABCA1, ATP-binding cassette transporter A1; ABCG1, ATP-binding cassette transporter G1; SR-BI, SR-B type I; RT-qPCR, quantitative real-time polymerase chain reaction.

TMP regulates $A B C A 1, A B C G 1, C D 36$ and $S R$ - $A$ expression and inhibits foam cell formation via PI3K/Akt-and p38-dependent pathways. Previous studies demonstrated that PI3K/Akt plays a crucial role in the uptake of modified lipoproteins and cholesterol efflux in various cells $(28,29)$. The present study detected whether PI3K/Akt was involved in the expression of scavenger receptors and ABC transporters in TMP-induced inhibition of formation of foam cells. As shown in Fig. 3, treatment with LY294002, a PI3K/Akt inhibitor, increased TMP-mediated downregulation of CD36 and SR-A and upregulation of ABCG1 protein expression, but not ABCA1 expression. It has been suggested that blockage of p38 MAPK signaling is involved in TMP-invoked inhibition of inflammation in endothelial cells (22). To clarify whether p38 is involved in TMP-regulated expression of ABC transporters and scavenger receptors, we examined the effects of SB203580 (a bicyclic imidazole compound, a specific inhibitor of p38 MAPK). We revealed that the inhibition of p38 only further increased TMP-induced ABCA1 protein expression in RAW264.7 macrophages (Fig. 4).

To further confirm whether TMP results in changes in foam cell formation-related proteins by affecting transcriptional 

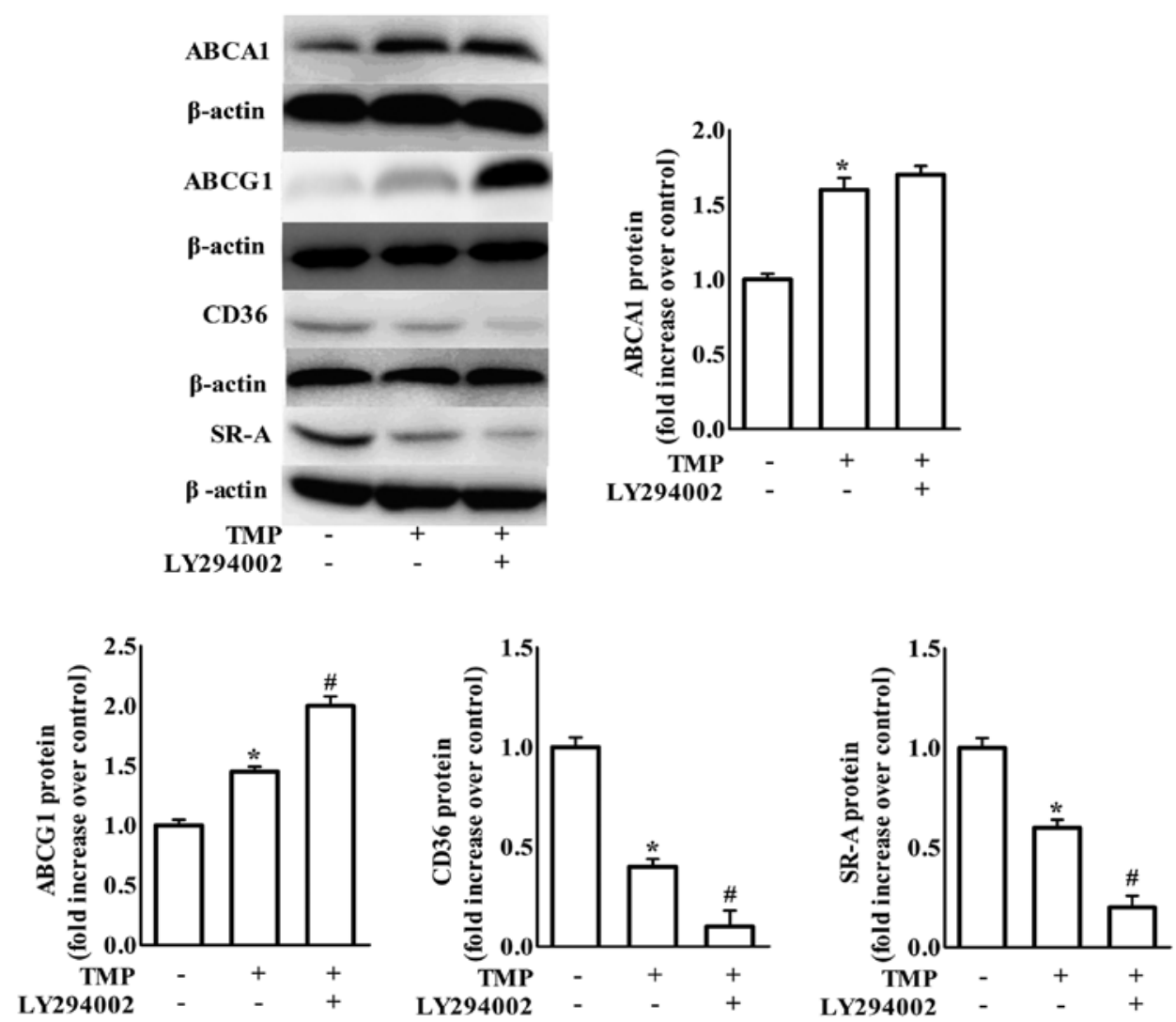

Figure 3. Inhibition of PI3K activation enhances the TMP-mediated protein expression of scavenger receptors and ATP-binding cassette transporters in RAW264.7 macrophages. Macrophages were pretreated with the PI3K inhibitor LY294002 for $1 \mathrm{~h}$ and then co-incubated with $50 \mu \mathrm{g} / \mathrm{ml}$ TMP for an additional $24 \mathrm{~h}$. Western blotting was used to assess protein expression. The results are expressed as the mean \pm SEM of 3 independent experiments; ${ }^{*} \mathrm{P}<0.05$ compared with the control group; ${ }^{~} \mathrm{P}<0.05$ compared with the TMP-treated group. TMP, tetramethylpyrazine.

levels, the mRNA levels of these proteins were also examined by real-time PCR in RAW264.7 macrophages. The findings in Fig. 5 revealed that treatment with the PI3K inhibitor LY294002 significantly enhanced the effects of TMP on the decrease of CD36 and SR-A gene expression. Meanwhile, the p38 inhibitor SB203580 treatment caused an increase in TMP-induced ABCA1 gene expression. Moreover, treatment with either the PI3K inhibitor LY294002 or the p38 inhibitor SB203580 increased TMP-induced ABCG1 gene expression. We further detected the effect of TMP on PI3K/Akt and p38 phosphorylation in RAW264.7 macrophages. The phosphorylation of PI3K/Akt and p38 was inhibited after $24 \mathrm{~h}$ of TMP treatment (Fig. 6A). Pretreatment with the p38 inhibitor SB203580 further increased the effects of TMP on the inhibition of $\mathrm{p} 38$ phosphorylation without affecting PI3K/Akt phosphorylation. In addition, pretreatment with the PI3K inhibitor LY294002 increased TMP-decreased PI3K/Akt phosphorylation, but not TMP-decreased p38 phosphorylation (Fig. 6B). These results revealed that TMP can inhibit PI3K/Akt and p38 phosphorylation independently in RAW264.7 macrophages. Combined with the data of Figs. 3-5, these results indicated that the effects of TMP on the upregulation of ABCA1 and ABCG1 expression and the downregulation of CD36 and SR-A expression were mediated by the inactivation of PI3K/Akt and $\mathrm{p} 38$.

We further investigated the effects of PI3K and p38 inhibition on TMP-mediated ox-LDL uptake, cholesterol efflux and intracellular lipid accumulation, which are necessary for macrophage-derived foam cell formation. As shown in Fig. 7A, TMP-decreased ox-LDL uptake in macrophages was exacerbated by LY294002, which was consistent with the enhanced effect of LY294002 on TMP-mediated scavenger receptors. However, SB203580 did not affect TMP-regulated ox-LDL uptake. ABCA1 promotes free cholesterol efflux from macrophages to ApoA1 and ABCG1 is responsible for cholesterol efflux to HDL (7-9). Therefore, we used separate experiments to investigate ABCA1- and ABCG1-regulated cholesterol efflux. The results in Fig. $7 \mathrm{C}$ revealed that TMP-increased ABCA1-regulated cholesterol efflux was increased by SB203580, which was consistent with the promotive effect of SB203580 on TMP-mediated upregulation of ABCA1. TMP-increased ABCG1-mediated cholesterol efflux was enhanced by LY294002, which was consistent with the reinforced effect of LY294002 on TMP-mediated ABCG1 expression (Fig. 7D). Additionally, the TMP-invoked inhibition of lipid accumulation in RAW264.7 macrophages was significantly enhanced by both LY294002 and SB203580 (Fig. 7B). These results revealed that the TMP-mediated changes in foam cell formation-related proteins in RAW264.7 macrophages were involved in the PI3K- and p38-signaling pathways. Hence, the inactivation of PI3K and p38 is necessary for the suppressive effects of TMP on macrophage-derived foam cell formation.

TMP decreases ABCAl protein stability, but does not affect $A B C G 1$ protein stability. The present study demonstrated that TMP upregulated the protein expression and mRNA 

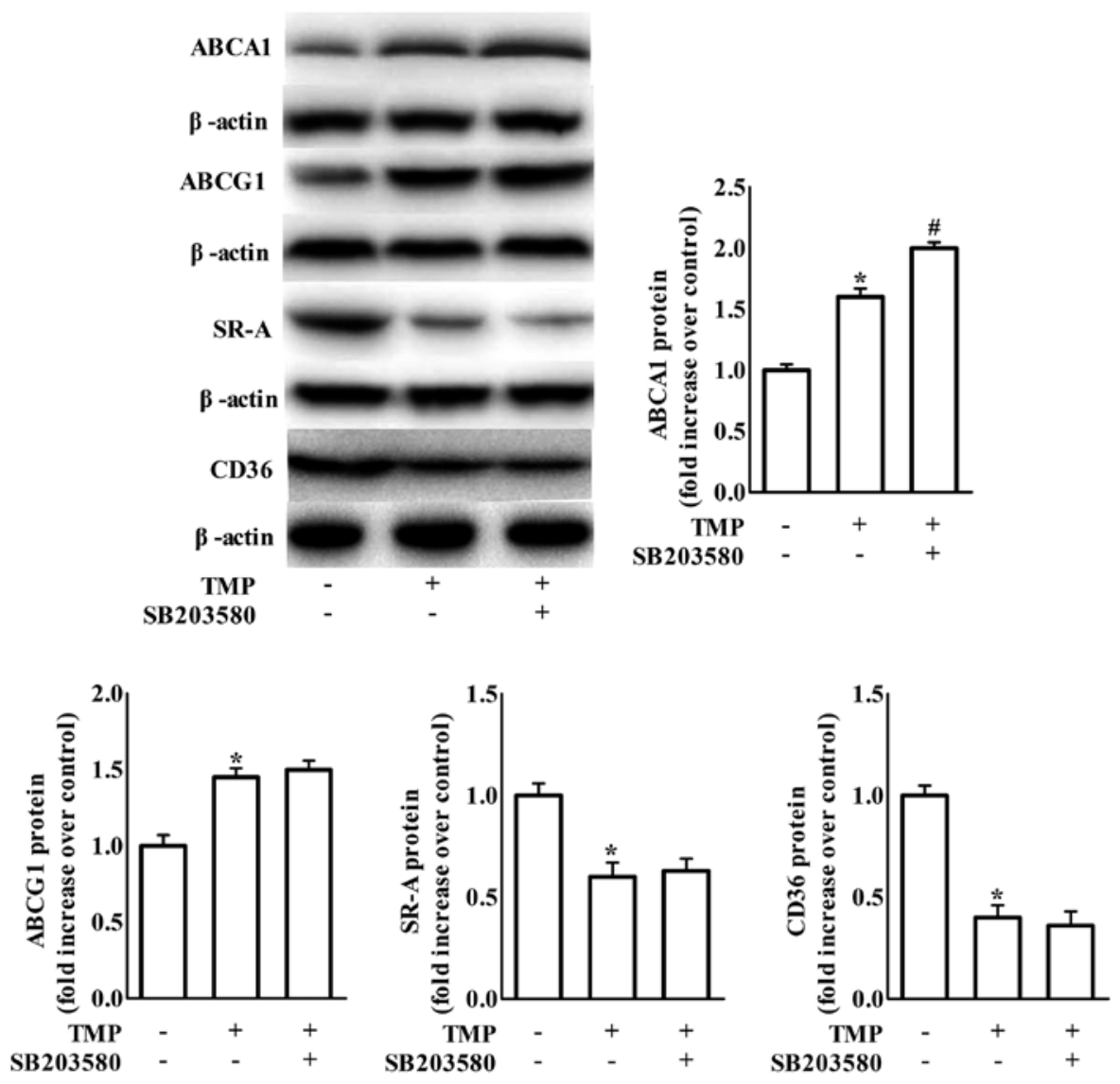

Figure 4. Inhibition of p38 activation enhances the TMP-mediated protein expression of scavenger receptors and ATP-binding cassette transporters in RAW264.7 macrophages. Macrophages were pretreated with the p38 inhibitor SB203580 for $1 \mathrm{~h}$ and then co-incubated with $50 \mu \mathrm{g} / \mathrm{ml} \mathrm{TMP}$ for an additional $24 \mathrm{~h}$. Western blotting was used to assess protein expression. The results are expressed as the mean \pm SEM of 3 independent experiments; ${ }^{*} \mathrm{P}<0.05$ compared with the control group; ${ }^{\sharp} \mathrm{P}<0.05$ compared with the TMP-treated group. TMP, tetramethylpyrazine.
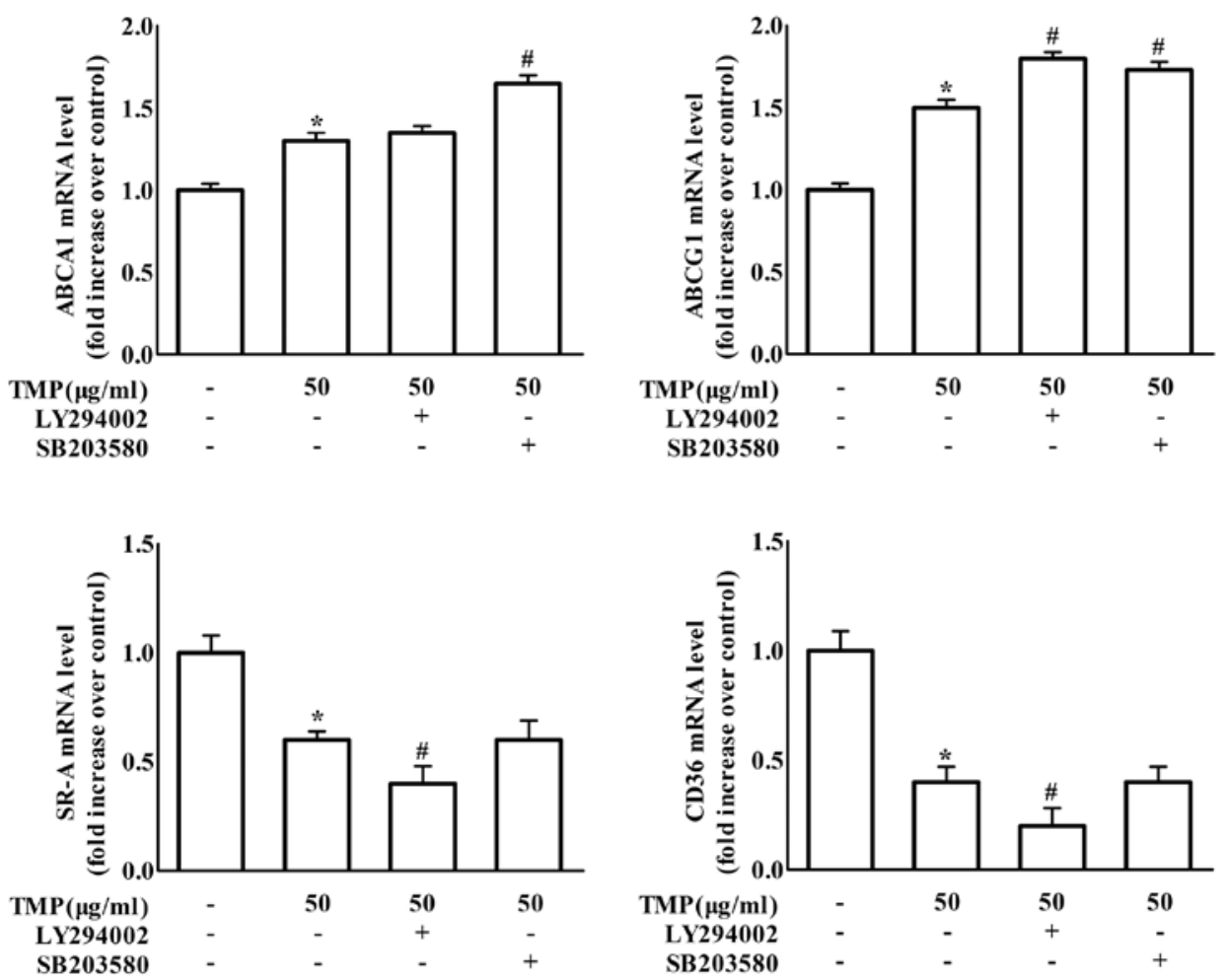

Figure 5. Inhibition of PI3K and $\mathrm{p} 38$ activation enhances the TMP-mediated mRNA expression of scavenger receptors and ATP-binding cassette transporters in RAW264.7 macrophages. Macrophages were pretreated with the PI3K inhibitor LY294002 or the p38 inhibitor SB203580 for $1 \mathrm{~h}$, and then co-incubated with $50 \mu \mathrm{g} / \mathrm{ml}$ TMP for an additional $24 \mathrm{~h}$. Real-time PCR was used to assess mRNA expression. The results are expressed as the mean \pm SEM of 3 independent experiments; " $\mathrm{P}<0.05$ compared with the control group; ${ }^{"} \mathrm{P}<0.05$ compared with the TMP-treated group. TMP, tetramethylpyrazine. 
$\mathbf{A}$
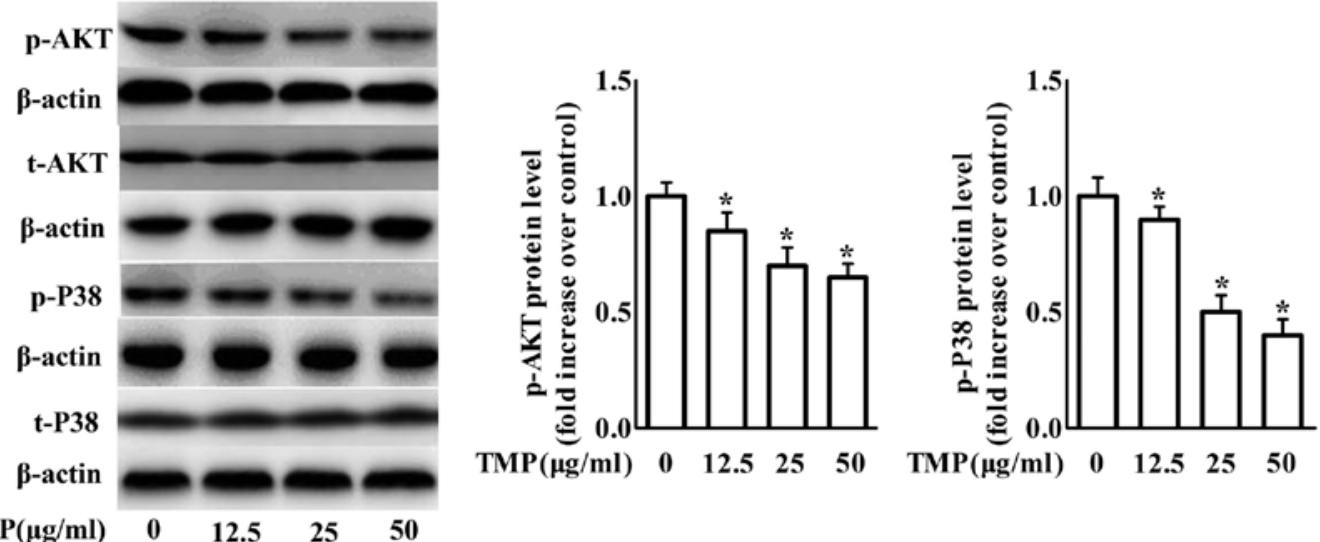

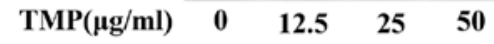
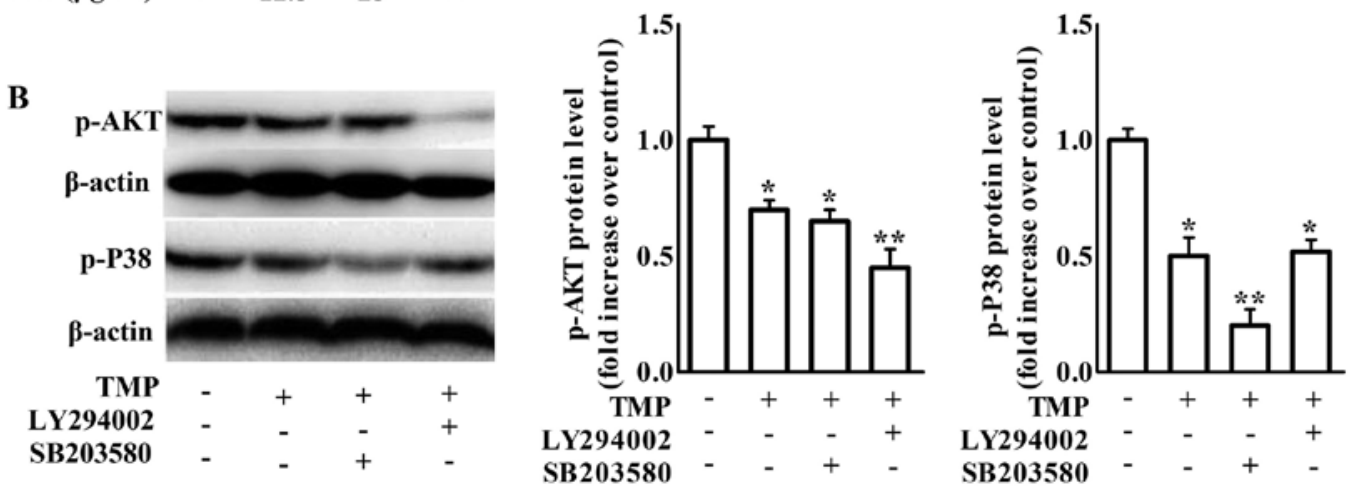

Figure 6. Inhibition of PI3K and p38 activation enhances the TMP-mediated effects on PI3K/Akt and p38 phosphorylation in RAW264.7 macrophages. (A) Macrophages were treated with TMP $(0,12.5,25$ and $50 \mu \mathrm{g} / \mathrm{ml})$ for $24 \mathrm{~h}$, and then the phosphorylation of PI3K/Akt and p38 were examined. (B) Macrophages were pretreated with the PI3K inhibitor LY294002 or the p38 inhibitor SB203580 for $1 \mathrm{~h}$ and then co-incubated with $50 \mu \mathrm{g} / \mathrm{ml}$ TMP for an additional $24 \mathrm{~h}$, phosphorylation of PI $3 \mathrm{~K} / \mathrm{Akt}$ and p38 are shown. The results are expressed as the mean \pm SEM of 3 independent experiments; ${ }^{*} \mathrm{P}<0.05$ compared with the control group; ${ }^{* *} \mathrm{P}<0.05$ compared with the TMP-treated group. TMP, tetramethylpyrazine.
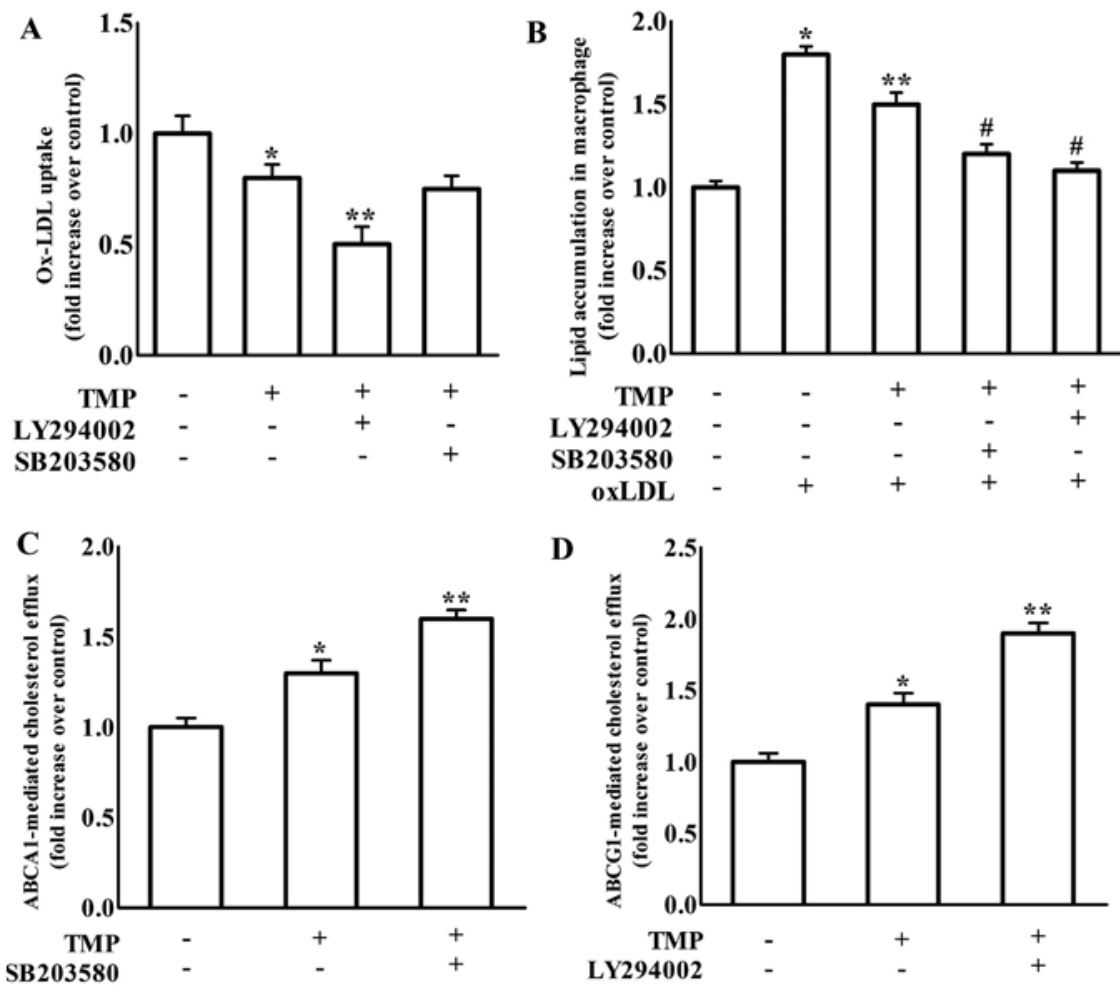

Figure 7. Inhibition of PI3K and p38 activation enhances the TMP-mediated effects on ox-LDL uptake, cholesterol efflux and lipid accumulation in RAW264.7 macrophages. Macrophages were pretreated with the PI3K inhibitor LY294002 or the p38 inhibitor SB203580 for $1 \mathrm{~h}$, and then co-incubated with $50 \mu \mathrm{g} / \mathrm{ml}$ TMP for an additional $24 \mathrm{~h}$. (A) ox-LDL uptake. (B) Lipid-loaded macrophages. (C) ABCA1-mediated cholesterol efflux. (D) ABCG1-mediated cholesterol efflux are shown. The results are expressed as the mean \pm SEM of 3 independent experiments; ${ }^{*} \mathrm{P}<0.05$ compared with the control group; ${ }^{* *} \mathrm{P}<0.05$ compared with the TMP-treated or ox-LDL-treated group; ${ }^{\prime} \mathrm{P}<0.05$ compared with the ox-LDL plus TMP-treated group. TMP, tetramethylpyrazine; ox-LDL, oxidized low-density lipoprotein; ABCA1, ATP-binding cassette transporter A1; ABCG1, ATP-binding cassette transporter G1. 

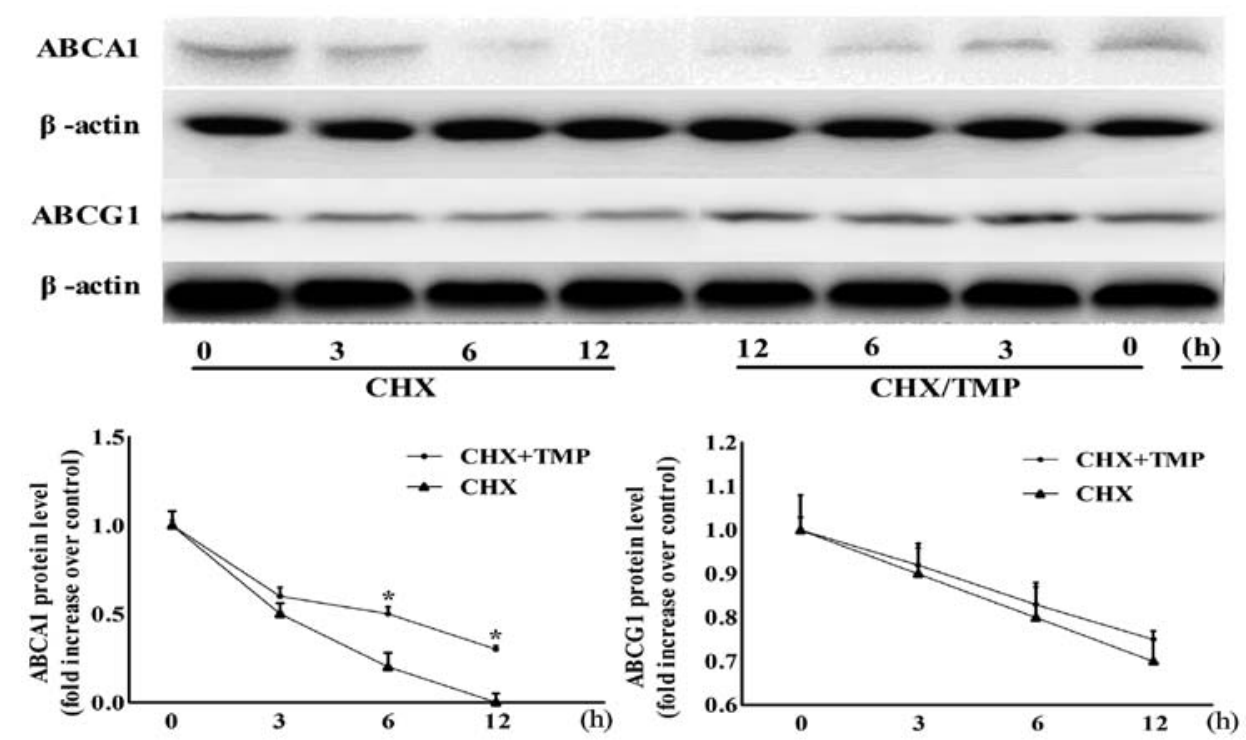

Figure 8. TMP enhances the protein stability of ABCA1. Macrophages were incubated with or without TMP $(50 \mu \mathrm{g} / \mathrm{ml})$ in the presence of CHX ( $2 \mu \mathrm{g} / \mathrm{ml})$ for the indicated time-points. Cellular lysates were subjected to western blotting to determine the levels of ABCA1, ABCG1 or $\beta$-actin. The data are representative of 3 independent experiments (mean \pm SEM); ${ }^{P} \mathrm{P}<0.05$ compared with the control group. TMP, tetramethylpyrazine; CHX, cycloheximide.

levels of ABCG1 and ABCA1, however, whether the protein stabilities of these proteins were affected by TMP remained to be examined. As shown in Fig. 8, no difference was found in the ABCG1 degradation between TMP-treated and control groups in the presence of $\mathrm{CHX}$ (an inhibitor of de novo protein synthesis) during a 12 -h period, indicating that TMP-increased ABCG1 expression was independent of protein stability. However, in the presence of CHX, the degradation rate of the ABCA1 protein was time-dependently suppressed by TMP.

TMP retards atherosclerotic lesion formation in Apo $E^{-1-}$ mice. We further examined the anti-atherogenic action of TMP in vivo. Sixteen week-old $\mathrm{ApoE}^{-/-}$mice treatment with TMP $(150 \mathrm{mg} / \mathrm{kg} / \mathrm{day})$ for 8 weeks markedly retarded lesion formation in atherosclerosis compared to the vehicle-fed ApoE $^{-/}$mice (Fig. 9A and B). Meanwhile, TMP decreased the protein expression of SR-A and CD36, but increased the protein expression of ABCG1 and ABCA1 in aortas (Fig. 9C). Our findings are in agreement with the results of the in vitro experiments.

\section{Discussion}

Tetramethylpyrazine (TMP) has been recognized as a protective agent against atherosclerosis (19-22). However, the effect and underlying mechanism by which TMP regulated lipid accumulation in macrophage-derived foam cells remained to be investigated. The present study, supplied novel insights into the molecular mechanisms of the antiatherogenic characteristic of TMP in $\mathrm{ApoE}^{-/-}$mouse aortas and in the macrophage-derived foam cell formation. TMP treatment suppressed ox-LDL uptake and induced cholesterol efflux, which are co-responsible for subsequent inhibition of lipid accumulation in macrophages. These effects can be attributed to decreased CD36 and SR-A expression, and to increased ABCG1 and ABCA1 in macrophages via inactivation of PI3K- and p38-dependent pathways. Moreover, TMP increased the expression of $\mathrm{ABCA} 1$ by increasing the protein stability of ABCA1. These findings revealed that TMP has a beneficial effect on sustaining lipid levels during the conversion of macrophages into foam cells in atherosclerosis lesion formation and this potential mechanism was described.

CD36 and SR-A are the main receptors for ox-LDL uptake, SR-BI along with ABCG1 and ABCA1 are amenable to cholesterol efflux. These actions play crucial roles in the regulation of intracellular lipid levels during foam cell formation (26). The present study may be the first to demonstrate that TMP inhibits intracellular lipid accumulation in macrophage-derived foam cells potentially through the decrease of ox-LDL uptake and the increase of cholesterol efflux. Moreover, TMP decreased both the mRNA and protein expression of CD36 and SR-A. CD36 and SR-A are two predominant types of scavenger receptors responsible for ox-LDL uptake in macrophages (26). Research utilizing LDL receptor knockout-mice $\left(\mathrm{LDLR}^{-1}\right)$ transplanted with SR-Adeficient fetal liver cells indicated that SR-A in macrophages is conducive to lesion formation of atherosclerosis. ApoE ${ }^{-1-}$ recipient mice injected with $\mathrm{CD} 36^{-/}$macrophages and fed with a high-fat diet revealed that CD36-dependent signaling cascades are essential for foam cell formation. Extensive studies also revealed that anti-atherogenic antioxidants can decrease the expression of SR-A and CD36, which indicate the crucial role of SR-A and CD36 in atherosclerotic pathogenesis (8). In the present study, we demonstrated that TMP suppresses ox-LDL uptake in macrophages via downregulation of the expression of SR-A and CD36, which could have resulted from the inhibition of the activity of the PI3K/Akt pathway. Notably, PI3K/Akt signaling inhibition enhanced the influence of TMP on SR-A and CD36 expression. These findings demonstrate that inhibition of PI3K/Akt signaling is necessary for the function of TMP athero-protection in macrophages. In view of the action of SR-A and CD36, the effect of TMP attenuation of SR-A and CD36 may facilitate the decrease of ox-LDL uptake and subsequent suppression of foam cell formation. 


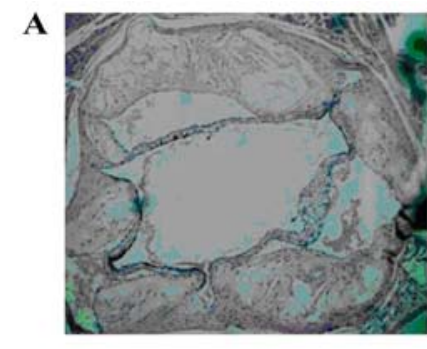

TMP(mg/kg) $\quad 0$

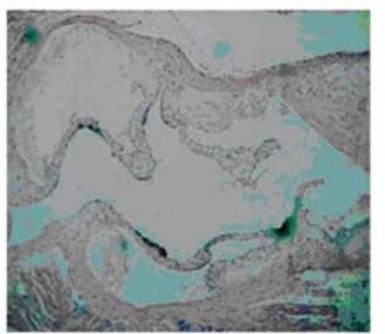

150

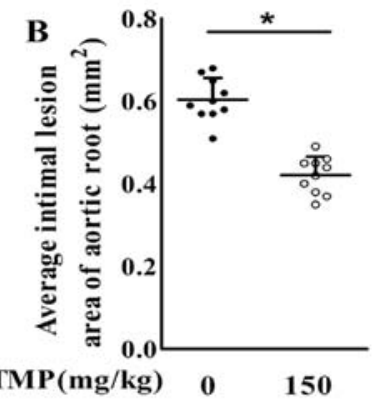

C
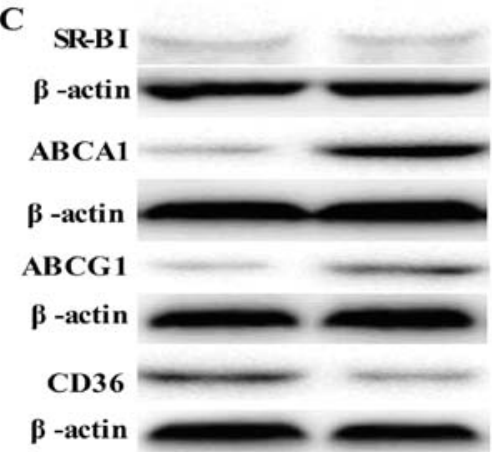

SR-A

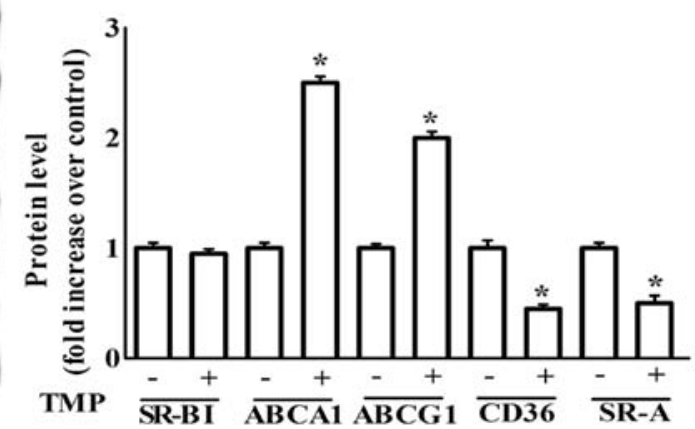

$\beta$-actin

Figure 9. TMP inhibits atherosclerotic lesion formation in $\mathrm{ApoE}^{-/}$mice via an increase in the expression of ABCA1 and ABCG1 and a decrease in the expression of CD36 and SR-A. (A) Representative H\&E stained aortic sections (magnification, $\mathrm{x} 40$ ). (B) Average size of the atherosclerotic plaques in the aortic root. Data are expressed as the mean \pm SEM ( $n=10$ for each group). (C) After the treatment of $\mathrm{ApoE}^{-/}$mice as described in the Materials and methods section, aortas were collected and subjected to western blotting to detect the protein expression of ABCA1, ABCG1, SR-BI, SR-A and CD36. One representative blot is shown. The relative protein levels of CD36, SR-A, SR-BI, ABCA1 and ABCG1 are presented as the mean \pm SEM of the optical density from 3 separate experiments; ${ }^{*} \mathrm{P}<0.05$ compared with the ApoE ${ }^{-/}$mice. TMP, tetramethylpyrazine; ApoE ${ }^{-/}$, apolipoprotein E-deficient; ABCA1, ATP-binding cassette transporter A1; ABCG1, ATP-binding cassette transporter G1; CD36, cluster of differentiation 36; SR-A scavenger receptor class A; SR-BI, SR-B type I.

Except for its suppressive effect on the expression of scavenger receptors, TMP increased the expression of ABCA1 and ABCA1-mediated cholesterol efflux via the inactivation of p38 signaling, and increased the expression of ABCG1 and ABCG1-mediated cholesterol efflux via the inactivation of PI3K/Akt signaling. The expression of ABCA1/ABCG1 was upregulated by the activation of Liver X receptor (LXR) signaling, thus promoting macrophage RCT (30) and decreasing atherosclerosis in mouse models (31). In addition, various antioxidants with anti-atherogenic properties are capable of upregulating the expression of ABCG1 and ABCA1 $(32,33)$. In view of the function of $A B C G 1$ and $A B C A 1$, the increasing effect of TMP on the expression of ABCG1 and ABCA1 observed in the present study may conduce to the inhibition of ox-LDL uptake and subsequent suppression of foam cell formation.

More crucially, ABCA1 protein was stabilized by TMP. This is in agreement with previous findings that revealed that stabilization of the ABCA1 protein increased cholesterol efflux and decreased lipid accumulation in foam cells (34). Conversely, destabilization of the ABCA1 protein induced cholesterol accumulation in macrophages and foam cell formation (35). Collectively, our results indicate that the increase of ABCA1 stability by TMP may facilitate the suppression of the formation of foam cells.

In addition to TMP-invoked ABCA1 protein stability, we also found that TMP increased the mRNA expression of
ABCA1. These data revealed the TMP-induced increase of the protein expression of ABCA1 via post-translational and transcriptional regulation.

These findings demonstrate that TMP inhibits foam cell formation but does not restrict the cell culture system. The in vivo study revealed that atherosclerotic progression in $\mathrm{ApoE}^{-/}$mice was retarded by TMP, which is conformable to a previous study (20). Indeed, TMP exhibited some beneficial effects on atherosclerosis such as preventing endothelial dysfunction (19), regulating lipid levels in the plasma (20), attenuating oxidative stress (21), and inhibiting inflammation (22). In the present study, we further found that TMP decreased the expression of CD36 and SR-A and increased the expression of ABCA1 and ABCG1 in TMP-treated ApoE ${ }^{-1-}$ mice. Therefore, it appears that these therapeutic actions are pervasive. Accordingly, TMP may play beneficial roles in different organs through disparate mechanisms.

In brief, the present study revealed that TMP decreased CD36 and SR-A expression and ox-LDL uptake via the inactivation of PI3K signaling. Furthermore, TMP increased the expression of ABCA1 and ABCA1-mediated cholesterol efflux via the inactivation of $\mathrm{p} 38$ signaling, and increased ABCG1 expression and ABCG1-mediated cholesterol efflux via the inactivation of PI3K signaling. This TMP-invoked regulation of the expression of CD36, SR-A, ABCA1 and ABCG1 resulted in the inhibition of foam cell formation induced by ox-LDL. The present study offered novel insights 
for better understanding the underlying mechanisms involved in TMP-invoked suppression of foam cell formation in atherosclerosis. The only limitation of this study is that we did not perform an LY294002 or SB203580 control without TMP, and the effects between TMP and LY294002 or SB203580 were not compared. Therefore, whether other signaling pathways are involved in the protection of TMP against macrophagederived foam cell formation remains to be investigated.

\section{Acknowledgements}

The present study was supported by grants from the Medical Association of Sichuan Province (S15040), the National Natural Science Fund (81500357), the Affiliated Hospital of Southwest Medical University, and the Beijing Medical Award Foundation.

\section{References}

1. Trigatti BL and Fuller M: HDL signaling and protection against coronary artery atherosclerosis in mice. J Biomed Res 30: 94-100, 2016.

2. Cai Y, Li JD and Yan C: Vinpocetine attenuates lipid accumulation and atherosclerosis formation. Biochem Biophys Res Commun 434: 439-443, 2013.

3. Tsai JY, Su KH, Shyue SK, Kou YR, Yu YB, Hsiao SH, Chiang AN, Wu YL, Ching LC and Lee TS: EGb761 ameliorates the formation of foam cells by regulating the expression of SR-A and ABCA1: Role of haem oxygenase-1. Cardiovasc Res 88: 415-423, 2010.

4. Rahaman SO, Swat W, Febbraio M and Silverstein RL: Vav family Rho guanine nucleotide exchange factors regulate CD36mediated macrophage foam cell formation. J Biol Chem 286: 7010-7017, 2011.

5. Chistiakov DA, Bobryshev YV and Orekhov AN: Macrophagemediated cholesterol handling in atherosclerosis. J Cell Mol Med 20: 17-28, 2016.

6. Fielding CJ and Fielding PE: Cellular cholesterol efflux. Biochim Biophys Acta 1533: 175-189, 2001.

7. McNeish J, Aiello RJ, Guyot D, Turi T, Gabel C, Aldinger C, Hoppe KL, Roach ML, Royer LJ, de Wet J, et al: High density lipoprotein deficiency and foam cell accumulation in mice with targeted disruption of ATP-binding cassette transporter-1. Proc Natl Acad Sci USA 97: 4245-4250, 2000.

8. Kennedy MA, Barrera GC, Nakamura K, Baldán A, Tarr P, Fishbein MC, Frank J, Francone OL and Edwards PA: ABCG1 has a critical role in mediating cholesterol efflux to HDL and preventing cellular lipid accumulation. Cell Metab 1: 121-131, 2005.

9. Haghpassand M, Bourassa PA, Francone OL and Aiello RJ: Monocyte/macrophage expression of ABCA1 has minimal contribution to plasma HDL levels. J Clin Invest 108: 1315-1320, 2001.

10. Zhao JF, Ching LC, Huang YC, Chen CY, Chiang AN, Kou YR, Shyue SK and Lee TS: Molecular mechanism of curcumin on the suppression of cholesterol accumulation in macrophage foam cells and atherosclerosis. Mol Nutr Food Res 56: 691-701, 2012.

11. Park SH, Paek JH, Shin D, Lee JY, Lim SS and Kang YH: Purple perilla extracts with $\alpha$-asarone enhance cholesterol efflux from oxidized LDL-exposed macrophages. Int J Mol Med 35: 957-965, 2015.

12. Zhang C, Yan W, Li B, Xu B, Gong Y, Chu F, Zhang Y, Yao Q, Wang $\mathrm{P}$ and Lei $\mathrm{H}$ : A new ligustrazine derivative-selective cytotoxicity by suppression of NF- $\kappa \mathrm{B} / \mathrm{p} 65$ and $\mathrm{COX}-2$ expression on human hepatoma cells. Part 3. Int J Mol Sci 16: 16401-16413, 2015.

13. Pan J, Shang JF, Jiang GQ and Yang ZX: Ligustrazine induces apoptosis of breast cancer cells in vitro and in vivo. J Cancer Res Ther 11: 454-458, 2015.

14. Ji AJ, Liu SL, Ju WZ and Huang XE: Anti-proliferation effects and molecular mechanisms of action of tetramethypyrazine on human SGC-7901 gastric carcinoma cells. Asian Pac J Cancer Prev 15: 3581-3586, 2014
15. Zeng Z, Zhu W, Zhou X, Jin Z, Liu H, Chen X, Pan J, Demura H, Naruse $M$ and Shi Y: Tetramethylpyrazine, a Chinese drug, blocks coronary vasoconstriction by endothelin-1 and decreases plasma endothelin-1 levels in experimental animals. J Cardiovasc Pharmacol 31 (Suppl 1): S313-S316, 1998.

16. Guo SK, Chen KJ, Qian ZH, Weng WL and Qian MY: Tetramethylpyrazine in the treatment of cardiovascular and cerebrovascular diseases. Planta Med 47: 89, 1983.

17. Dai XZ and Bache RJ: Coronary and systemic hemodynamic effects of tetramethylpyrazine in the dog. J Cardiovasc Pharmacol 7: 841-849, 1985.

18. Liu SY and Sylvester DM: Antithrombotic/antiplatelet activity of tetramethylpyrazine. Thromb Res 58: 129-140, 1990.

19. Ni X, Wong SL, Wong CM, Lau CW, Shi X, Cai Y and Huang Y: Tetramethylpyrazine protects against hydrogen peroxideprovoked endothelial dysfunction in isolated rat aortic rings: Implications for antioxidant therapy of vascular diseases. Evid Based Complement Alternat Med 2014: 627181, 2014.

20. Wang GF, Shi CG, Sun MZ, Wang L, Wu SX, Wang HF, Xu ZQ and Chen DM: Tetramethylpyrazine attenuates atherosclerosis development and protects endothelial cells from ox-LDL. Cardiovasc Drugs Ther 27: 199-210, 2013.

21. Jiang F, Qian J, Chen S, Zhang W and Liu C: Ligustrazine improves atherosclerosis in rat via attenuation of oxidative stress. Pharm Biol 49: 856-863, 2011.

22. Li XY, He JL, Liu HT, Li WM and Yu C: Tetramethylpyrazine suppresses interleukin-8 expression in LPS-stimulated human umbilical vein endothelial cell by blocking ERK, p38 and nulear factor-kappaB signaling pathways. J Ethnopharmacol 125: 83-89, 2009.

23. Kang Q, Liu W, Liu H and Zhou M: Effect of compound Chuanxiong capsule on inflammatory reaction and PI3K/ $\mathrm{Akt} / \mathrm{NF}-\kappa \mathrm{B}$ signaling pathway in atherosclerosis. Evid Based Complement Alternat Med 2015: 584596, 2015.

24. Hu Y, Sun B, Liu K, Yan M, Zhang Y, Miao C and Ren L: Icariin attenuates high-cholesterol diet induced atherosclerosis in rats by inhibition of inflammatory response and p38 MAPK signaling pathway. Inflammation 39: 228-236, 2016.

25. Chen Z, Huo JR, Yang L and Zhu HY: Effect of ligustrazine on mice model of hepatic veno-occlusive disease induced by Gynura segetum. J Gastroenterol Hepatol 26: 1016-1021, 2011.

26. Li XY, Kong LX, Li J, He HX and Zhou YD: Kaempferol suppresses lipid accumulation in macrophages through the downregulation of cluster of differentiation 36 and the upregulation of scavenger receptor class B type I and ATP-binding cassette transporters A1 and G1. Int J Mol Med 31: 331-338, 2013.

27. Lin YT, Jian DY, Kwok CF, Ho LT and Juan CC: Visfatin promotes foam cell formation by dysregulating CD36, SRA ABCA1, and ABCG1 expression in RAW264.7 macrophages. Shock 45: 460-468, 2016

28. Lin CS, Lin FY, Ho LJ, Tsai CS, Cheng SM, Wu WL, Huang CY, Lian CH, Yang SP and Lai JH: PKCD signalling regulates SR-A and CD36 expression and foam cell formation. Cardiovasc Res 95: 346-355, 2012.

29. Huang CX, Zhang YL, Wang JF, Jiang JY and Bao JL: MCP-1 impacts RCT by repressing ABCA1, ABCG1, and SR-BI through PI3K/Akt posttranslational regulation in HepG2 cells. J Lipid Res 54: 1231-1240, 2013.

30. Naik SU, Wang X, Da Silva JS, Jaye M, Macphee CH, Reilly MP, Billheimer JT, Rothblat GH and Rader DJ: Pharmacological activation of liver $\mathrm{X}$ receptors promotes reverse cholesterol transport in vivo. Circulation 113: 90-97, 2006.

31. Terasaka N, Hiroshima A, Koieyama T, Ubukata N, Morikawa Y, Nakai D and Inaba T: T-0901317, a synthetic liver X receptor ligand, inhibits development of atherosclerosis in LDL receptordeficient mice. FEBS Lett 536: 6-11, 2003.

32. Rana M, Kumar A, Tiwari RL, Singh V, Chandra T, Dikshit M and Barthwal MK: IRAK regulates macrophage foam cell formation by modulating genes involved in cholesterol uptake and efflux. BioEssays 38: 591-604, 2016.

33. Gui YZ, Yan H, Gao F, Xi C, Li HH and Wang YP: Betulin attenuates atherosclerosis in $\mathrm{apoE}^{-/-}$mice by up-regulating ABCA1 and ABCG1. Acta Pharmacol Sin 37: 1337-1348, 2016.

34. Li X, Zhou Y, Yu C, Yang H, Zhang C, Ye Y and Xiao S: Paeonol suppresses lipid accumulation in macrophages via upregulation of the ATP-binding cassette transporter A1 and downregulation of the cluster of differentiation 36. Int J Oncol 46: 764-774, 2015.

35. Fu Y, Mukhamedova N, Ip S, D'Souza W, Henley KJ, DiTommaso T, Kesani R, Ditiatkovski M, Jones L, Lane RM, et al: ABCA12 regulates ABCA1-dependent cholesterol efflux from macrophages and the development of atherosclerosis. Cell Metab 18: 225-238, 2013. 